\title{
Two-Dimensional Model of a Space Station Freedom Thermal Energy Storage Canister
}

Thomas W. Kerslake

Lewis Research Center

Cleveland, Ohio

and

Mounir B. Ibrahim

Cleveland State University

Cleveland, Ohio

\section{Prepared for the}

25th Intersociety Energy Conversion Engineering Conference cosponsored by the AIChE, SAE, ACS, AIAA, ASME, and IEEE Reno, Nevada, August 12-17, 1990 

TWO-DIMENSIONAL MODEL OF A SPACE STATION FREEDOM THERMAL ENERGY STORAGE CANISTER

\author{
Thomas W. Kers lake \\ National Aeronautics and Space Administration \\ Lewis Research Center \\ Cleveland, Ohio 44135 \\ and \\ Mounir B. Ibrahim \\ Department of Mechanical Engineering \\ Cleveland State University \\ Cleveland, $\mathrm{OH} 44115$
}

\section{ABSTRACT}

The Solar Dynamic Power Module being developed for Space Station Freedom uses a eutectic mixture of $\mathrm{LiF}_{-} \mathrm{CaF}_{2}$ phase-change salt contained in toroidal canisters for thermal energy storage. This paper presents results from heat transfer analyses of the phase-change salt containment can-

* ister. A two-dimensional, axisymmetric finitedifference computer program which models the canister walls, salt, void, and heat engine working fluid coolant was developed. Analyses included effects of conduction in canister walls and solid salt, conduction and free convection in liquid salt, conduction and radiation across salt vapor filled void regions and forced convection in the heat engine working fluid. Void shape, location, growth or shrinkage (due to density difference between the solid and liquid salt phases) were prescribed based on engineering judgement. The salt phase change process was modeled using the enthalpy method. Discussion of results focuses on the role of free-convection in the liquid salt on canister heat transfer performance. This role is shown to be important for interpreting the relationship between ground-based canister performance (in 1-g) and expected on-orbit performance (in micro-g). Attention is also focused on the influence of void heat transfer on canister wall temperature distributions. The large thermal resistance of void regions is shown to accentuate canister hot spots and temperature gradients.

\section{NOMENCLATURE}

void surface element area, $\mathrm{cm}^{2}$ or cons tant
L

$\mathrm{LiF}_{-} \mathrm{CaF}_{2}$ lithium fluoride-calcium difluoride

MFL PCM mass fraction liquid

NRS number of void radiating surface elements

$\mathrm{Nu} \quad$ Nusselt number

PCM phase change material

Q thermal power,

T

TES

t

VVF

z

$\Delta$

$\delta$

$\varepsilon$

$\rho$

$\sigma$

\section{Subscripts:}

$\begin{array}{ll}\text { i } & \text { inner radius } \\ \text { j } & \text { void surface element } \\ \text { k } & \text { void surface element } \\ \text { L } & \text { liquid PCM } \\ \text { m } & \text { PCM melt } \\ \text { o } & \text { outer radius }\end{array}$


S

$\mathrm{v}$

WS

w. solid PCM

void

side wall

canister wall

\section{INTRODUCTION}

Electrical power for NASA's proposed Space Station Freedom will be generated by photovoltaic solar arrays initially and later augmented with Solar Dynamic Power Modules (SDPM's). The SDPM employs a concentrator to collect and focus solar energy into a cylindrical cavity heat receiver where it is converted to thermal energy. A fraction of the thermal energy is transferred to a circulating working fluid to operate a heat engine and produce electrical power. The remaining thermal energy melts a eutectic composition LiF-CaF 2 Phase Change Material (PCM) contained in multiple canisters located concentrically around working fluid tubes running the length of the heat receiver cavity shown conceptually in figure 1. A single PCM containment canister is shown in figure 2 . The PCM stores and releases thermal energy by undergoing phase change at its critical temperature of $1040 \mathrm{~K}$. This permits continuous operation of the heat engine during the substantial eclipse periods (up to $36 \mathrm{~min}$ ) of Freedom's low earth orbit. The service life requirement for the heat receiver is 30 years.

In previous work by the authors [1], computer programs were developed to analyze PCM containment canister thermal performance using the enthalpy method. First, approximate one-dimensional analyses were conducted to estimate the effects of PCM void vapor heat transfer and liquid PCM free convection on canister thermal performance. Second, two-dimensional $(\mathrm{r}, \mathrm{z})$, or $2 \mathrm{D}(\mathrm{r}, \mathrm{z})$, axisymmetric canister analyses were conducted wi thout the presence of a PCM vapor void or liquid PCM free convection. Results from these analyses indicated that the presence of a one-dimensional void increased peak containment canister wall temperatures as much as $200 \mathrm{~K}$. The presence of free convection lowered wall temperatures as much as $170 \mathrm{~K}$ and lowered PCM temperature gradients by a factor of $\sim 3$ times in addition to increasing PCM melting rate by $\sim 13$ percent. However, twodimensional results indicated that a large portion (about 50 percent) of PCM containment canister radial heat transfer occurred in the container metallic walls and not in the PCM. Therefore, it was postulated that the effects of a void and free convection would be much less dramatic when two-dimensional analyses were conducted.

To quantify the effects of a void and free convection, the $2 \mathrm{D}(\mathrm{r}, \mathrm{z})$ canister computer program described in [1], was extended to include a void model and a free convection model. Figure 3 illustrates the PCM containment canister schematic problem geometry. This paper presents results from two-dimensional PCM containment canister numerical analyses which include a PCM vapor void and liquid PCM free convertion.
The PCM vapor void model includes a prescribed void shape and location. Void heat transfer occurs via uncoupled vapor thermal conduction and internal void surface radiation. Liquid PCM free convection is modeled by use of an enhanced liquid PCM thermal conductivity which is based on the Nusselt number (Nu). Results are discussed in a comparative manner, highlighting significant differences in PCM containment canister temperature and phase distributions that arise from the inclusion of a void and free convection.

\section{ANALYSIS}

The governing equation for energy redistribution in the PCM and canister walls is conservation of energy. The conservation equation was formulated using "the enthalpy method" as follows

$$
\frac{\partial(\rho e)}{\partial t}=\operatorname{div}(k \nabla T)
$$

where $e$ is specific enthalpy given in joules per gram [2]. Specific enthalpy is coupled to temperature through the following set of constitutive equat ions:

$$
\begin{aligned}
& \mathrm{T}_{\mathrm{m}}+\mathrm{e} / \mathrm{c}_{\mathrm{S}} \quad: \mathrm{e}<0 \quad \text { Solid PCM } \\
& T=\begin{array}{lll}
T_{m} & : 0 \leq e \leq H_{m} & \text { Mushy PCM } \\
T_{m}+\left(e-H_{m}\right) / C_{L}: H_{m}<e & \text { Liquid PCM }
\end{array} \\
& \mathrm{T}_{\mathrm{m}}+e / c_{\mathrm{w}} \quad:-\infty<e<\infty \text { Canister Walls }
\end{aligned}
$$

Here, $T_{m}$ is the PCM melting temperature, $H_{m}$ is the PCM heat of fusion, and $\mathrm{CS}_{S}, \mathrm{CL}_{L}$, and $\mathrm{C}_{W}$ are the specific heat values for the solid PCM, liquid PCM, and canister wall material, respectively. A thorough discussion of the governing equations, boundary conditions, material properties, and numerical method used in this analysis are described in [1]. The PCM vapor void model is discussed below.

\subsection{PCM Vapor Void Model}

Due to receiver design requirements and PCM contraction during solidification, a fraction of the containment canister total volume consists of PCM vapor void at all times during the orbital cycle. The void volume fraction (VVF) yaries between 8 percent, when all PCM is liquid at the melting point $\left(\mathrm{T}_{\mathrm{m}}\right)$, to 22 percent, when all PCM is solid at $T_{m}$. The small volume changes associated with thermal expansion of the PCM and containment canister walls are ignored. The void geometry selected was a cylindrical annulus which easily conformed to the cylindrical finite-difference element grid network. The void was placed adjacent to the canister outer wall, a location that will generate conservatively high canister wall temperature distributions (figure 3). Void growth or shrinkage occur uniformly 
across the PCM-void interface defined as $r_{V}$. As PCM liquifies or freezes, $r_{V}$ increases or decreases, respectively, about $0.1 \mathrm{~cm}$ which changes void volume. The associated PCM growth or shrinkage is accommodated numerically by the combination of variable radial grid size and a variable PCM computational domain. This procedure, known as the "combined grid element technique," is described in [1]. However, at the time of this writing, the PCM growth-shrinkage computer algorithm was not thoroughly checked-out and thus, was not incorporated into these analyses. Therefore, as an engineering approximation, a constant 15 percent VVF was assumed.

It has been shown that both void vapor conduction and radiation are important elements of void heat transfer [1]. Since the void vapor pressure is small $\left(7 \times 10^{-3}\right.$ torr at $\left.1040 \mathrm{~K}\right)$, vapor mass is negligible $\left(10^{-8} \mathrm{~g}\right)$. Therefore, the void vapor temperature distribution can be determined by the steady state heat diffusion equation:

$$
\frac{1}{r} \frac{\partial}{\partial r}\left(r \frac{\partial T}{\partial r}\right)+\frac{\partial}{\partial z}\left(\frac{\partial T}{\partial z}\right)=0 .
$$

Preliminary void conduction calculations show that axial temperature gradients are small and can be ignored for engineering calculations. This eliminates the second term in equation (3). The solution to equation ( 3 ) has the familiar form

$$
T(r)=A \ln (r)+B
$$

with the constant $A=\left\{T\left(r_{O}\right)-T\left(r_{V}\right)\right\} / \ln \left(r_{0} / r_{V}\right)$ and the constant $\mathrm{B}=\mathrm{T}\left(\mathrm{r}_{\mathrm{O}}\right)-\ln \left(\mathrm{r}_{\mathrm{O}}\right)\left\{\mathrm{T}\left(\mathrm{r}_{\mathrm{O}}\right)-\mathrm{T}\left(\mathrm{r}_{\mathrm{V}}\right)\right\} /$ $\ln \left(r_{0} / r_{V}\right)$. Equation $(4)$ can be evaluated at each axial void grid element to determine the void vapor temperature distribution.

Void vapor thermal conductivity, $k_{\mathrm{V}}$, was estimated as in [2] using the kinetic theory of gases. Based on this theory, $\mathrm{k}_{\mathrm{v}}$ can be numerically evaluated using the following equation:

$$
\mathrm{k}_{\mathrm{V}}=1.457 \times 10^{-5} * \mathrm{~T}^{1 / 2} .
$$

In this equation, $\mathrm{k}_{\mathrm{V}}$ has the units $\mathrm{W} / \mathrm{cm}-\mathrm{K}$ and the temperature, $T$ (in degrees $K$ ), is determined by equation (4).

Void radiation heat transfer is calculated based on the assumptions that, (1) all void surfaces are diffuse and gray, (2) PCM surfaces are opaque to all wavelengths of radiation, and (3) void vapor is a nonparticipating medium. With these assumptions, the governing equation set for void radiation heat transfer is:

$$
\sum_{j=1}^{N R S}\left[\frac{\Delta_{k j}}{\varepsilon_{j}}-\left(\frac{1-\varepsilon_{j}}{\varepsilon_{j}}\right) F_{k j} \frac{Q_{j}}{A_{j}}\right]=\sum_{j=1}^{N R S} F_{k j} \sigma\left(T_{k}^{4}-T_{j}^{4}\right) \text {, }
$$

where $k$ indexes from 1 to NRS [3]. In equation (6), $k$ and $j$ are void surface element numbers that take on all integer values between 1 and NRS. NRS is the total number of radiating surfaces in the void enclosure. The term $\Delta_{k j}$ is the Kronecker delta function equal to 1.0 for $k=j$ and equal to 0.0 for $k \neq j$. Given that each surface element temperature, $T_{j}$, emittance, $\varepsilon_{j}$, and element-to-element view factor, $F_{k j}$, are known, the surface element net radiative heat loss matrix, $Q_{j} / A_{j}$, can be determined. These heat loss terms are then added to the energy balance equations for the appropriate finite-difference grid elements in the canister outer wall, canister side walls, and outermost PCM.

An emittance value of 0.52 was selected for canister walls which are fabricated of Haynes alloy 188 (HA 188). This value is based on experimental measurements from diffuse (grit blasted) HA 188 test coupons for the temperature range 1000 to $1100 \mathrm{~K}$. An emittance value of 0.6 was selected for PCM surfaces. This value is an estimate based on emit tance data for similar dielectric materials in the temperature range of interest. Element-to-element view factors, $F_{k j}$, were determined using existing closed-form view factor solutions and considerable view factor algebra. View factors can be recalculated as void size varies during the melt-freeze cycle.

\section{RESULTS}

In the absence of applicable exact or analytical solutions, previous numerical solutions, and experimental data, numerical consistency checks were performed to assess the validity of numerical solutions. A numerical check of canister model energy balance and void surface element view factor summation was carried out for each computer run. For all cases, an energy balance was maintained within 0.0015 percent and all surface element view factors summed to 1.0 within machine accuracy.

\subsection{Canister With Void}

Figure 4 illustrates canister temperature contour and PCM phase maps at four times (24.28. $48.56,69.80$, and $81.94 \mathrm{~min})$ during a $91 \mathrm{~min}$ orbital melt-freeze cycle. The PCM melting portion of the cycle occurs from time $=0$ to $\sim 55 \mathrm{~min}$ while PCM freezing occurs for the remaining portion of the cycle from time $=\sim 55$ to $\sim 91 \mathrm{~min}$. Initially, all PCM is solid at time $=0 \mathrm{~min}$. During the PCM melting period, the large void thermal resistance forces a large percentage of canister heat transfer to occur via canister walls. This is illustrated in figure $4(a)$ which shows high temperature gradients in the void region and isotherm normals (i.e., the direction of heat flow) generally aligned parallel to canister walls. Thus, energy absorbed in the canister outer wall diffuses around the void, down the side walls, and then into the PCM. As a consequence of this heat flow pattern, PCM melting occurs axially inward from'both side walls. By time $=48.56 \mathrm{~min}$ when $\sim 90$ percent of the PCM is liquid (figure 4(b)), heat transfer axially along the canister inner wall initiates PCM melting radially outward until all the PCM is liquified at time $=\sim 55 \mathrm{~min}$.

During PCM freezing, the heat of fusion energy liberated is transferred to the engine working fluid that cools the canister inner wall and to the canister outer wall where radiative heat loss to the receiver cavity occurs. Because the void acts 
as a thermal insulator, much of the heat loss from the liquid PCM to the canister outer wall occurs via conduction in canister side walls. As a consequence of this heat flow pattern, PCM freezing occurs along the canister inner wall and along the void surface and the maximum side wall temperature exists at about the radial midpoint (figure $4(\mathrm{c})$ ). Near the end of the orbital cycle at time $=81.94 \mathrm{~min}, \sim 90$ percent of the PCM is frozen and the last remaining liquid PCM exists adjacent to void (figure $4(\mathrm{~d})$ ). Side wall radial temperature profiles have been reestablished with temperature increasing in the positive radial direction. This is due to a small radiative heat input to the canister outer wall from the receiver cavity during the last $\sim 18$ min of the orbital cycle.

Figure 5 illustrates the corresponding canister temperature contour and PCM phase maps for a $91 \mathrm{~min}$ melt-freeze cycle which includes free convection in the liquid PCM. Figure $5(\mathrm{a})$ is identical to figure 4 (a) since the liquid PCM Rayleigh number (Ra) is below the critical Ra and liquid PCM heat transfer is still dominated by conduction. Thus, no convective heat transfer enhancement takes place during the early part of the orbital cycle. At about 30 min into the cycle, the critical Ra is exceeded and the $\mathrm{Nu}$ begins steadily increasing from 1.0 to a value of 4.5 at the end of the melting period $(\sim 55 \mathrm{~min})$. Free convection in the liquid increases the rate of PCM melting and decreases canister temperature gradients as shown in figure $5(\mathrm{~b})$ where $\mathrm{Nu}=3.047$. During the PCM freezing portion of the cycle, liquid convective effects quickly die out and the $\mathrm{Nu}$ falls back to 1.0 by $\sim 60 \mathrm{~min}$ into the cycle. Thus, for the majority of the PCM freezing period, liquid PCM heat transfer is dominated by conduction. Hence, figures 5(c) and (d) are nearly identical to figures 4 (c) and (d) with the exception that slightly more liquid PCM exists at the times of comparison for the case with free convection, i.e., the values of MFL (PCM mass fraction liquid) are slightly greater.

Figure 6 illustrates void radial heat transfer, Qvoid, as a function of time during the orbital melt-freeze cycle. Qvoid is comprised of vapor conduction and surface-to-surface radiation components . By convention, these components are taken as positive if the resulting heat transfer is radially inward. During PCM melting, void heat transfer via radiation is about 3 times greater than that by vapor conduction and both components are positive and remain fairly constant. During PCM freezing, radiation is about 2 times greater than vapor conduction and both components remain negative until $\sim 85$ min into the cycle when all the PCM has frozen. The jump in the curves at $\sim 72 \mathrm{~min}$ is associated with the outer wall radiative heat flux boundary condition going from negative to positive. The fact that both components of void heat transfer remain negative from $\sim 72$ to $\sim 85 \mathrm{~min}$ has interesting implications for the canister heat flow pattern. For this time period, relatively warm PCM transfers heat radially outward across the void to the canister outer wall where it is then transferred back down the canister side wall and into the engine working fluid coolant (figures $4(d)$ and $5(d)$ ).

\subsection{Canister Performance Comparison}

In this section, results from three canister analytical cases are compared: (1) without a void [1], (2) with a void, and (3) with a void and liquid PCM free convection. Comparison of results from cases 1 and 2 is intended to show the impacts of a void on canister heat transfer performance. Comparison of results from cases 2 and 3 is intended to show likely canister performance differences during ground testing (in 1-g) and flight operation (in micro-g).

Figure 7 illustrates the maximum canister wall temperature, $T(r, z)_{\max }$, throughout the 91 min orbital cycle for cases 1 to 3 . $T(r, z)$ max occurs at the axial midpoint of the outer wall and does not vary in position with time. The introduction of a void increases $T(r, z)_{\max }$ about $20 \mathrm{~K}$ during the PCM melting period ( 0 to $\sim 55 \mathrm{~min}$ ) and decreases $\mathrm{T}(\mathrm{r}, \mathrm{z})_{\max }$ about $10 \mathrm{~K}$ during the PCM freezing period $(\sim 55$ to $\sim 91 \mathrm{~min})$. These changes are associated with the large void thermal resistance which increases canister outer wall temperature gradients to conduct heat around the void. In addition, the void increases outer wall axial temperature gradients by 100 percent and increases side wall radial temperature gradients by $\sim 80$ percent during the PCM melting period.

The inclusion of liquid PCM free convection reduces $\mathrm{T}(\mathrm{r}, \mathrm{z})_{\max } 0$ to $10 \mathrm{~K}$ for the time between $\sim 30$ and $\sim 55$ min and has essentially no effect during other time periods (figure 7 ). It is interesiing to note that although convective effects moderate the increase in $\mathrm{T}(\mathrm{r}, \mathrm{z})_{\max }$ during $\mathrm{PCM}$ melting, total PCM liquification occurs earlier than for the case without free convection. Thus, sensible heating of the liquid PCM occurs and quickly increases $\mathrm{T}(\mathrm{r}, \mathrm{z})_{\max }$ to about the same value that is predicted for the case without free convection.

Figure 8 illustrates the fraction of total canister radial heat transfer (comprised of void conduction, void radiation, and canister wall conduction) that occurs by conduction in the two canister side walls. This "side wall fraction" was evaluated at the radial location corresponding to the inner surface of the outer canister wall, $\mathrm{R}_{\mathrm{O}}{ }^{-}$. The side wall fraction is a quantitative measure of how effectively canister walls redistribute energy absorbed in the outer wall and also provides a qualitative indication of wall temperature sensitivity to void location. The side wall fraction is relatively constant at $\sim 70$ percent for the case with a void. Large perturbations in side wall fraction occur for brief periods of time at $\sim 55, \sim 72$, and $\sim 85 \mathrm{~min}$. The three perturbations are associated with two step changes in the outer wall heat flux boundary condition and the point of complete PCM liquification, respectively. For the case without a void, the side wall fraction is considerably lower, i.e., 30 to 50 percent, due to the relatively high thermal conductance of the PCM when compared to the void. The same three perturbations exist as in the case with the void in addition to another perturbation at $\sim 62 \mathrm{~min}$. This last perturbation is associated with a $\sim 7 \mathrm{~min}$ period (from $\sim 55$ to $\sim 62$ min) during which a thin layer of PCM freezes along the outer wall. Once frozen, relatively large 
temperature gradients exist within the PCM layer which reduces the side wall fraction to only a couple percent at $62^{+} \min$.

\section{DISCUSSION}

Results from 2D $(r, z)$ canister analyses show that the largest changes in $T(r, z)_{\max }$ due to free convection and the introduction of a void are $\sim-10$ and $\sim+20 \mathrm{~K}$, respectively. These changes are an order-of-magnitude lower than the changes predicted from one-dimensional analyses [1]. Therefore, this confirms the postulation that the effects of free convection and a void on canister thermal performance are much less pronounced in a two-dimensional analysis than in a one-dimensional analysis because of the large heat transfer contribution of canister side walls [1].

\subsection{On The Effects Of Free Convection}

Al though relatively large Nu numbers exist during the PCM melting period, the length of time in which they occur is short. Thus over this short period of time, canister thermal performance in a 1-g environment, defined in terms of maximum wall temperature, canister temperature gradients, and PCM melting rate and/or PCM utilization, is not greatly different from that expected in a micro-g environment. For canisters in the receiver cavity containing high quality two-phase PCM, a small reduction in maximum wall temperature and a small increase in PCM utilization would be expected during 1-g operation as a consequence of liquid PCM convection. Canisters that contain completely liquified PCM would experience approximately the same thermal cycle during $1-g$ and micro-g operation while canisters containing low quality two-phase PCM would be essentially unaffected. Therefore, within the scope of this analysis, results indicate that canister thermal performance during ground tests should not be significantly different than that expected on-orbit.

The reader should be reminded that implicit in these results are the assumptions of (1) axisymmetry (which requires alignment of the gravity vector and the canister axis of symmetry), (2) constant radiative flux input conditions at the canister outer wall in each case considered, and (3) a prescribed void shape and location. Assumption 1 restricts the validity of analytical results to a ground test configuration with the canister axis vertical and with circumferentially uniform outer wall heating. Assumption 2 limits the available latitude for direct case-to-case comparison of results since large differences in canister temperature predictions invalidates the assumption of identical outer wall heat flux conditions in each case. This holds true since the canister outer wall boundary condition is a func$t i o n$ of the radiation environment in the receiver cavity as well as canister outer wall temperature. Assumption 3 removes the possibility of different void shapes and locations that are likely to occur between 1-g canister tests and micro-g canister operation. However, the canister performance differences associated with void shape and more importantly, void location, are bounded by results from two cases considered in this paper, i.e., a canister without a void and a canister with a void con- servatively located adjacent to the outer wall. This assumption is further discussed in the following section.

\subsection{On The Effects of The Void}

The conservative placement of a vapor-filled void volume adjacent to the canister outer wall generates the two negative effects of increased wall temperatures and increased wall temperature gradients (when compared to the case without void) during PCM melting. These effects increase canister thermal stresses and decrease canister service life predictions based on cumulative creep damage theory. Introduction of a void also reverses the sign of the side wall temperature gradient during the first half of the PCM freezing period which does not occur in the case without a void. The resulting change in the canister side wall thermal-stress distribution and the resulting impact (good, bad or indifferent) on canister life prediction is not easily determined wi thout detailed structural analysis.

A potentially beneficial effect of a void placed at the canister outer wall is a reduction in canister heat loss (more precisely, canister heat exchange with other canisters in the receiver cavity and heat loss out the cavity aperture) during PCM freezing due to the insulating quality of the void. The greatest canister heat loss occurs in the hottest canisters located near the aperture end of the receiver cavity (figure 1). These canisters are also located on the coolant tube near the inlet manifold and are thus cooled by relatively low temperature heat engine working fluid. Reduction of heat loss from these hot test canisters permits greater heat transfer to the relatively cool working fluid near the inlet end of the coolant tube thereby decreasing the required working fluid heat transfer of canisters further down-stream. This, in turn, reduces the required temperature of downstream canisters which must transfer heat to the highest temperature working fluid.

The prescribed void shape and location were chosen to permit a relatively straight forward numerical analysis and to generate conservative predictions of canister temperatures and stresses. To confirm that void heat transfer and void placement are conservative, consider the relationship between maximum canister wall temperature and the radial heat transfer side wall fraction. As shown in figures 7 and 8 , the canister wall radial heat transfer contribution can double (i.e., side wall fraction increases by $\sim 2$ times) with only a $20 \mathrm{~K}$ increase in maximum wall temperature during PCM melting. Since the side wall fraction, by definition, is bounded by a 100 percent value, further increases in canister wall heat transfer are limited to $\sim 40$ percent. Thus, regardless of the nature of void heat transfer, the increase in maximum canister wall temperature from introduction of a void is bounded by $\sim 28 \mathrm{~K}$ or a $\mathrm{T}(\mathrm{r}, \mathrm{z})_{\max }$ of $1105 \mathrm{~K}$ for these cases. This $T(r, z)_{\max }$ value is just slightly higher than that predicted for the canister with void case (figure 7). Additionally, for any other viable void shape and location, PCM would be placed in contact with the outer wall thereby lowering the side wall fraction (figure 8, "no void" curve) and hence, lowering the maximum wall temperature. Therefore, 
differences in void shape and location between canister 1-g ground tests and micro-g operation lead to relatively small changes in predicted canister thermal performance which are essentially bounded by the void cases considered in this paper.

\section{SUMMARY OF RESULTS}

Results from two-dimensional analyses of the PCM containment canister without a void, with a void, and with a void plus liquid PCM free convection revealed several attributes of canister thermal performance. For engineering purposes, the change in canister thermal performance from $1-g$ to micro-g environments (due to free convection) was expected to be small if the canister ground test configuration was consistent with analytical assumptions. The introduction of a void and its associated poor heat transfer qualities increased maximum canister wall temperatures by $\sim 20 \mathrm{~K}$ and nearly doubled canister wall temperature gradients over those values predicted for the case without a void. At the same time, it was shown that wall temperature increases are bounded for any given case. It was also shown that for any viable void shape and location encountered during 1-g or micro-g operation, predicted

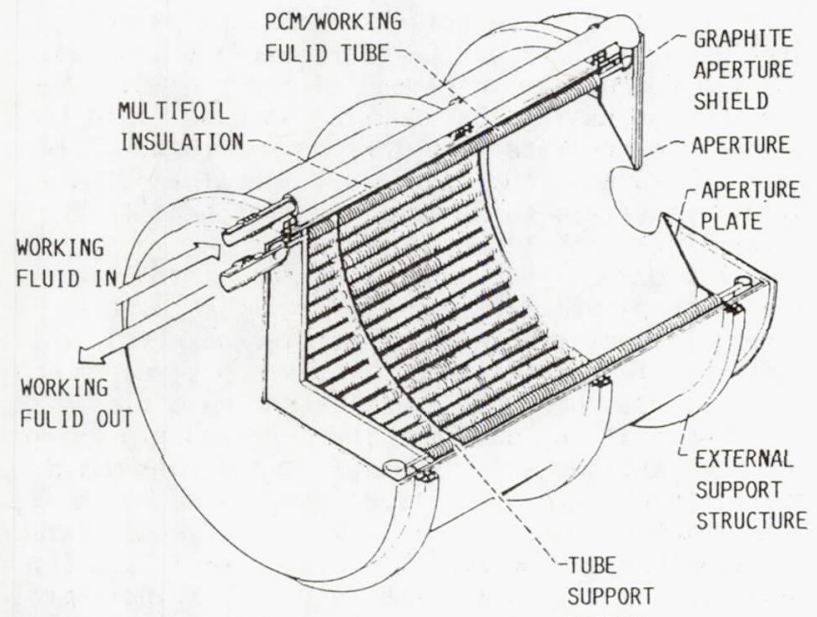

OVERALL DIMENSIONS

DIAMETER $186 \mathrm{cM}$

LENGTH $299 \mathrm{cM}$

FIGURE 1. - HEAT RECEIVER. canister thermal performance differences were small and the limits of canister thermal performance were known .

\section{ACKNOWLEDGEMENTS}

The authors wish to express thanks to Mr. Chris A. Gallo, NASA Lewis Research Center, for producing the temperature contour and PCM phase plots contained in this report.

\section{REFERENCES}

1. Kerslake, Thomas W. and Ibrahim, Mounir B., Analysis of Thermal Energy Storage Material with Change-of-Phase Volumetric Effects. Proceedings of the Twelf th Annual ASME International Solar Energy Conference, ASME, New York, 1990, pp. 315-325. (see also, NASA TM-102457).

2. Wichner, R.P., et al., "Thermal Analysis of Heat Storage Canisters for a Solar Dynamic, Space Power System", ORNL/TM-10665. April 1988.

3. Siegel, Robert, and Howell, Iohn R., Thermal Radiation Heat Transfer: 2nd Edition. Hemisphere Publishing Corporation, 1981, pp. 243.

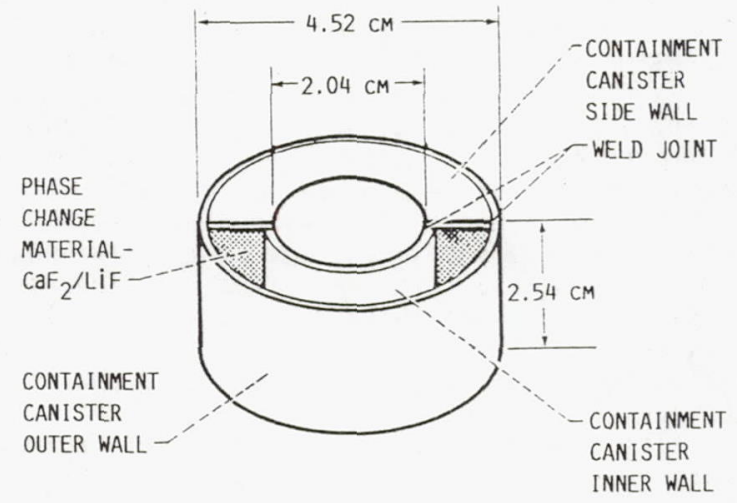

FIGURE 2. - PCM CONTAINMENT CANISTER (HAYNES ALLOY 188).

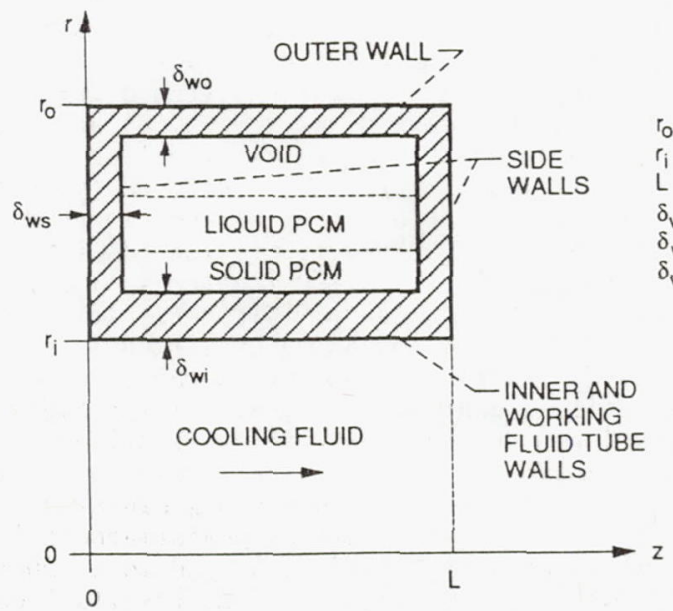

FIGURE 3. - SCHEMATIC PROBLEM GEOMETRY. $r_{0}=2.261 \mathrm{~cm}$ $r_{i}=1.022 \mathrm{~cm}$ $L=2.540 \mathrm{~cm}$ $\delta_{\text {wo }}=0.152 \mathrm{~cm}$ $\delta_{w i}=0.165 \mathrm{~cm}$ $\delta_{w s}=0.152 \mathrm{~cm}$ 

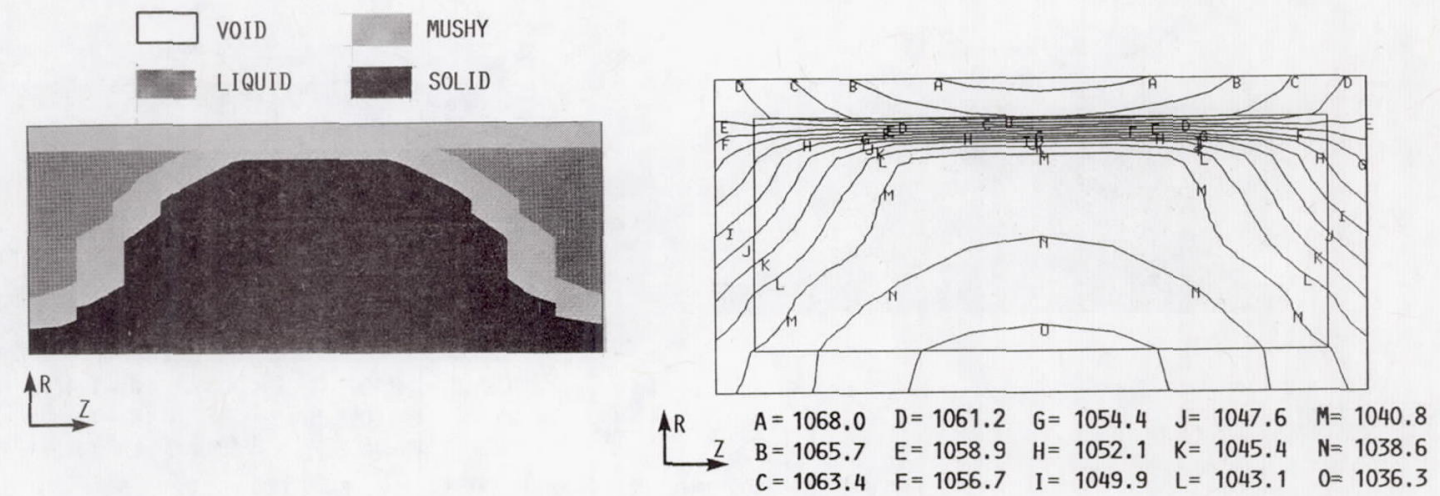

(a) TIME $=24.28$ MIN MFL $=0.3244 \quad$ VVF $=0.1507 \quad \mathrm{NU}=1.000$
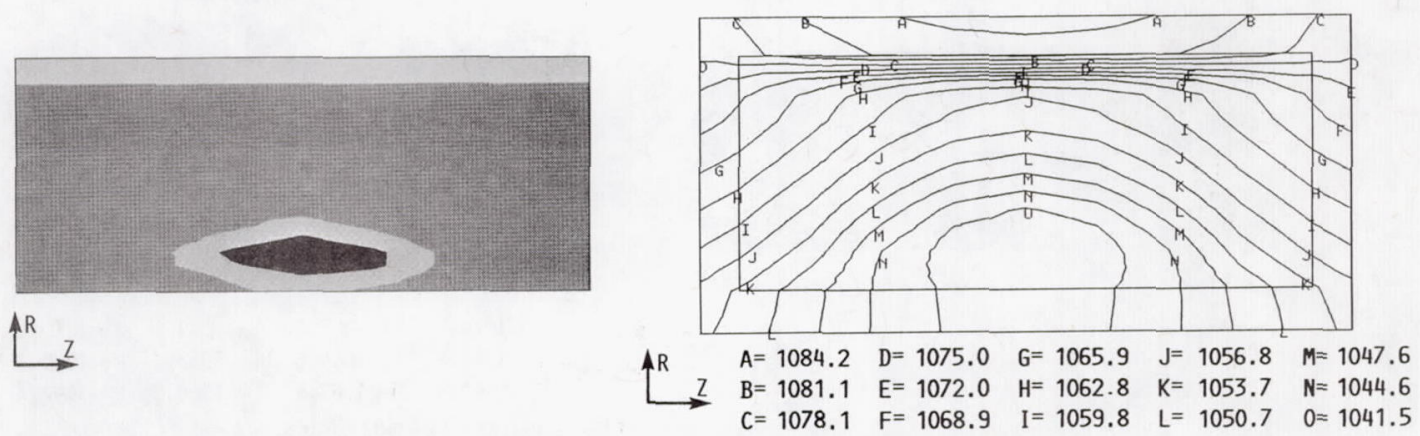

(b) TIME $=48.56$ MIN MFL $=0.9097 \quad$ VVF $=0.1507 \quad \mathrm{NU}=1.000$
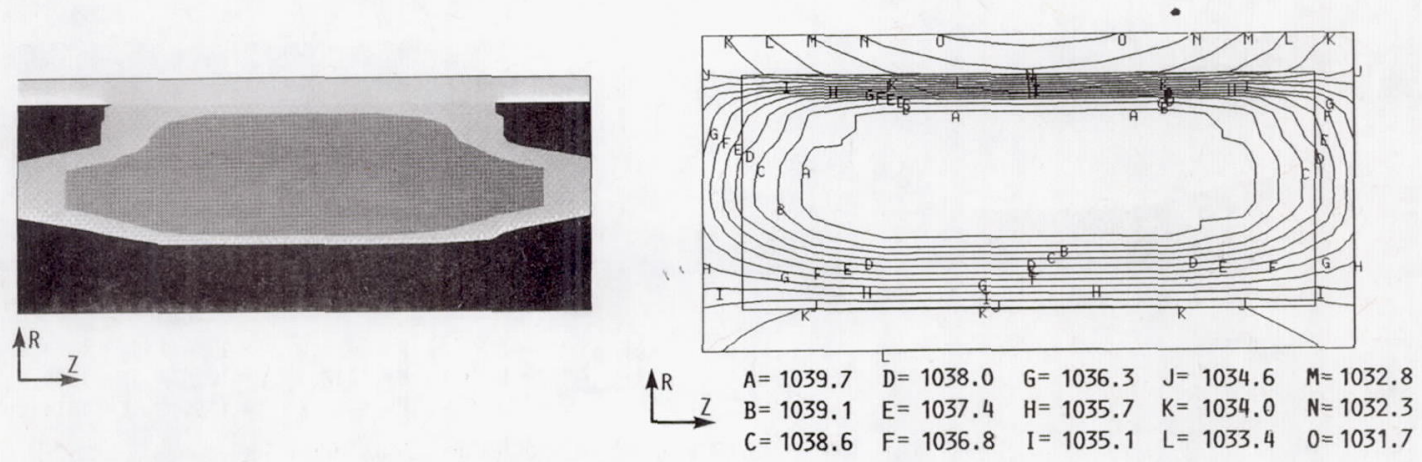

(c) TIME $=69.80$ MIN MFL $=0.5137 \quad$ VVF $=0.1507 \quad \mathrm{NU}=1.000$
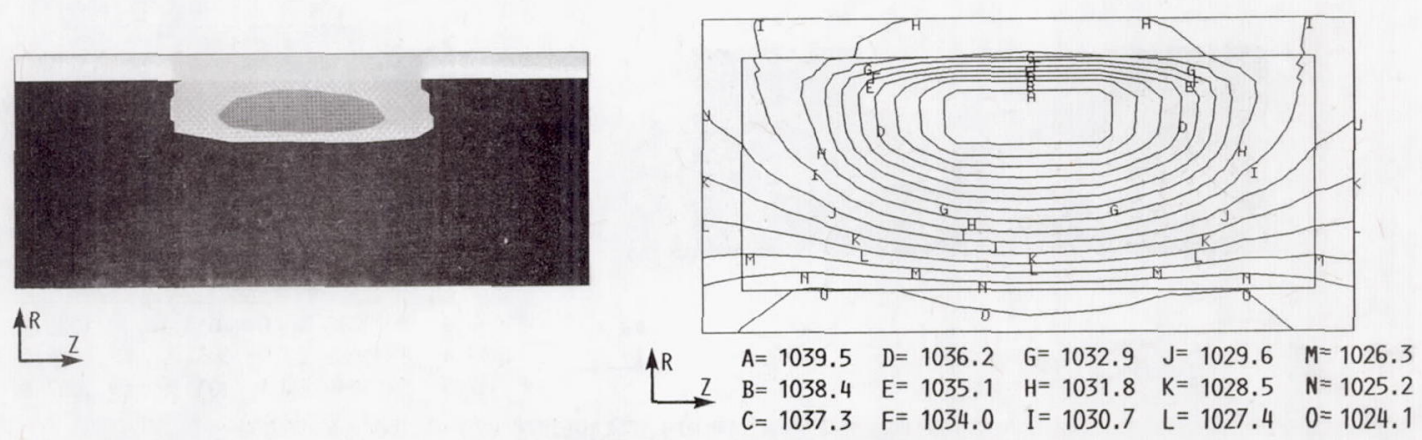

(d) TIME $=81.94 \mathrm{MIN}$ MFL $=0.0933 \quad$ VVF $=0.1507 \quad \mathrm{NU}=1.000$

FiguRE 4. - CANISTER TEMPERATURE CONTOUR (DEg K) AND PCM PHASE MAPS WITHOUT FREE CONVECTION. 

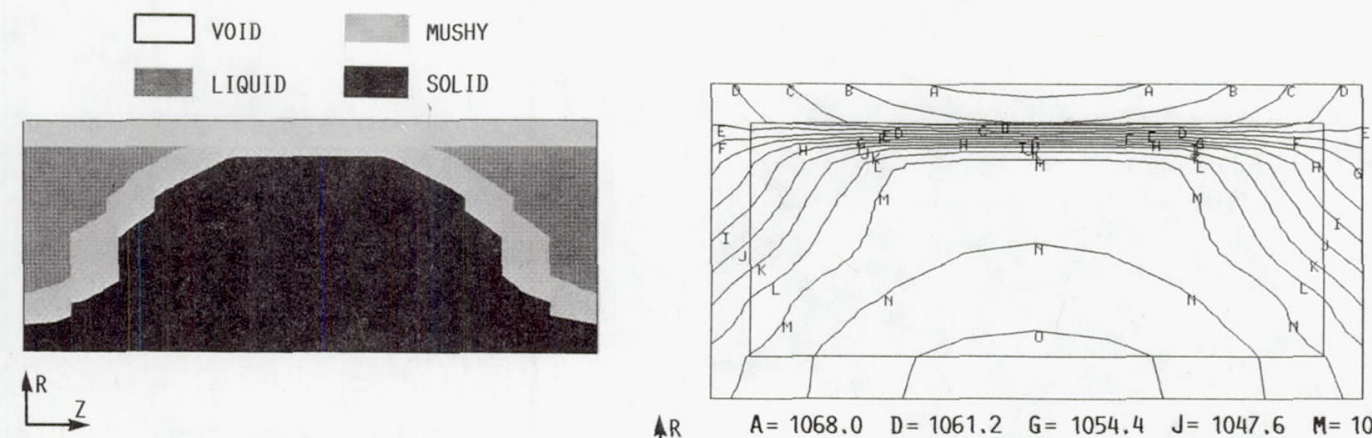

AR $\quad A=1068.0 \quad D=1061.2 \quad G=1054.4 \quad J=1047.6 \quad M=1040.8$ Z $\quad B=1065.7 \quad E=1058.9 \quad H=1052.1 \quad K=1045.4 \quad N=1038.6$ $C=1063.4 \quad F=1056.7 \quad I=1049.9 \quad L=1043.1 \quad 0=1036.3$

(a) TIME $=24.28$ MIN MFL $=0.3244 \quad$ VVF $=0.1507 \quad \mathrm{NU}=1.000$
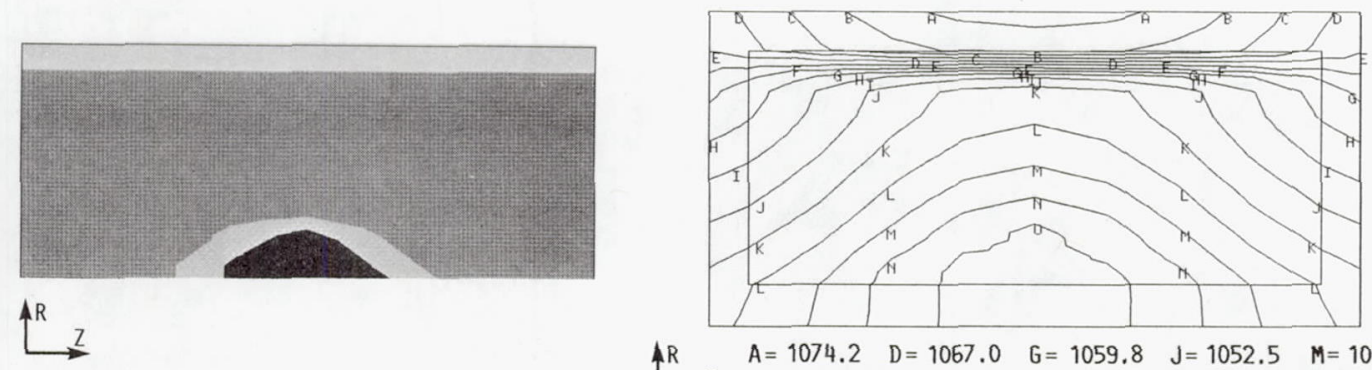

AR $A=1074.2 \quad D=1067.0 \quad G=1059.8 \quad J=1052.5 \quad M=1045.3$ $\begin{array}{llll}\mathrm{B}=1071.8 & \mathrm{E}=1064.6 \quad \mathrm{H}=1057.3 \quad \mathrm{~K}=1050.1 \quad \mathrm{~N}=1042.9\end{array}$

(b) TIME $=48.55$ MIN MFL $=0.9397 \quad$ VVF $=0.1507 \quad \mathrm{NU}=3.047$
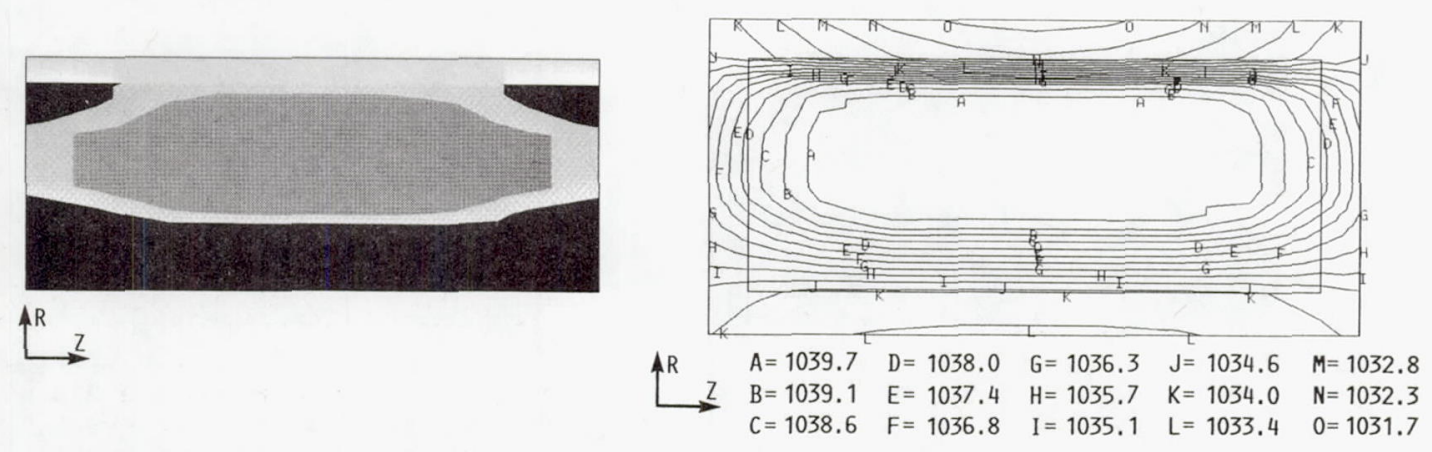

(c) TIME $=69.80 \mathrm{MIN}$ MFL $=0.5305 \quad$ VVF $=0.1507 \quad \mathrm{NU}=1.000$
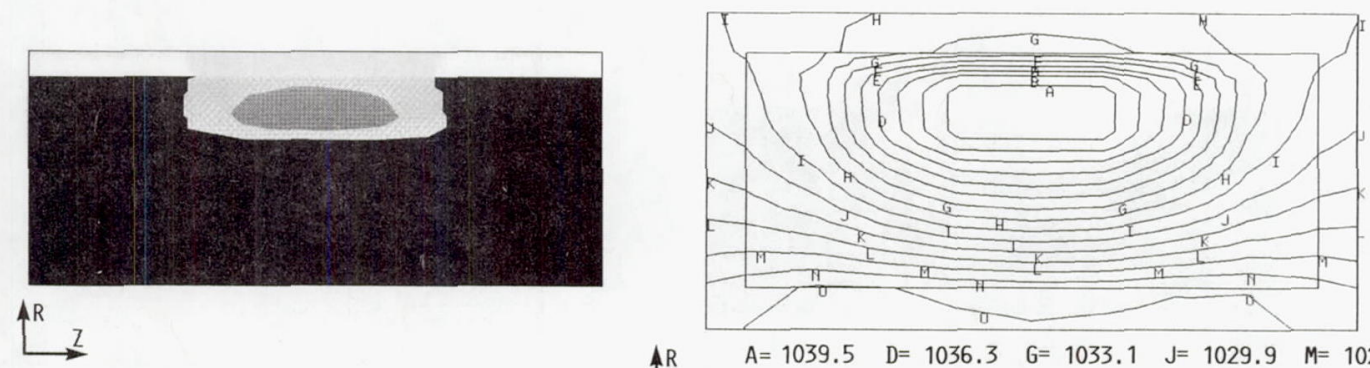

AR $A=1039.5 \quad D=1036.3 \quad G=1033.1 \quad J=1029.9 \quad M=1026.7$

$\longrightarrow \mathrm{B}=1038.4 \quad \mathrm{E}=1035.2 \quad \mathrm{H}=1032.0 \quad \mathrm{~K}=1028.9 \quad \mathrm{~N}=1025.7$ $C=1037.3 \quad F=1034.2 \quad I=1031.0 \quad L=1027.8 \quad 0=1024.6$

(d) TIME $=81.94 \quad \mathrm{MIN} \quad \mathrm{MFL}=0.1074 \quad \mathrm{VVF}=0.1507 \quad \mathrm{NU}=1.000$

FiguRE 5. - CANister teMPERATURE CONTOUR (DEG K) AND PCM PHASE MAPS WITH FREE CONVECTION. 


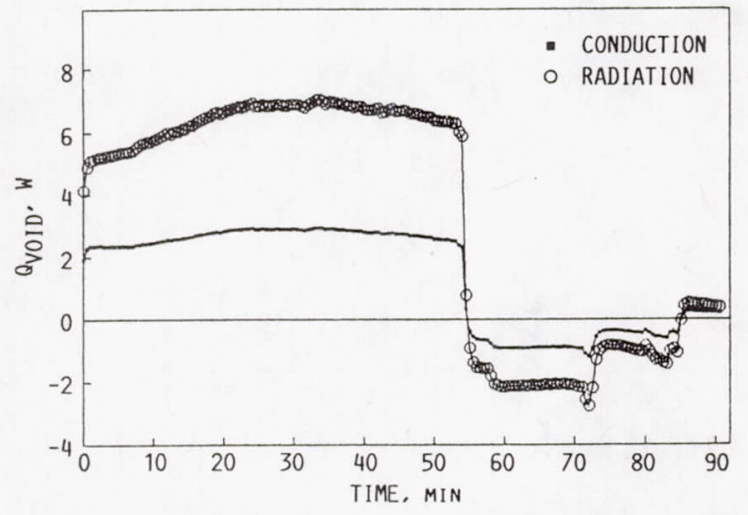

FIGURE 6. - VOID RADIAL HEAT TRANSFER.

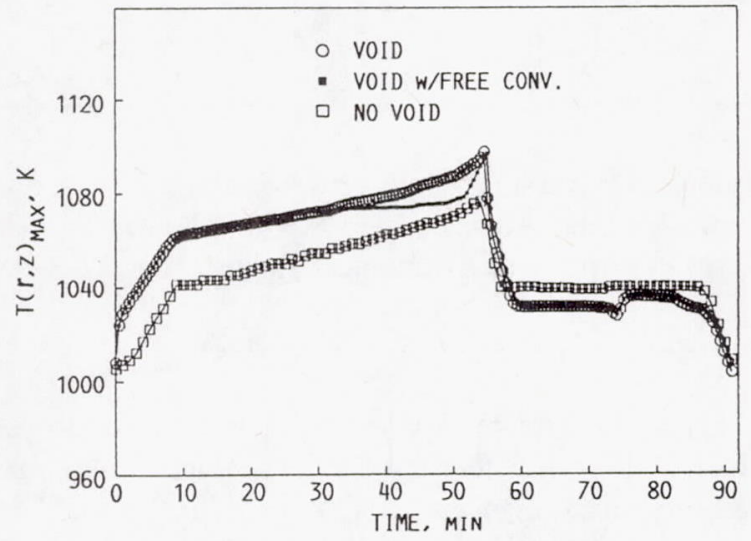

FIGURE 7. - MAXIMUM CANISTER WALL TEMPERATURE.

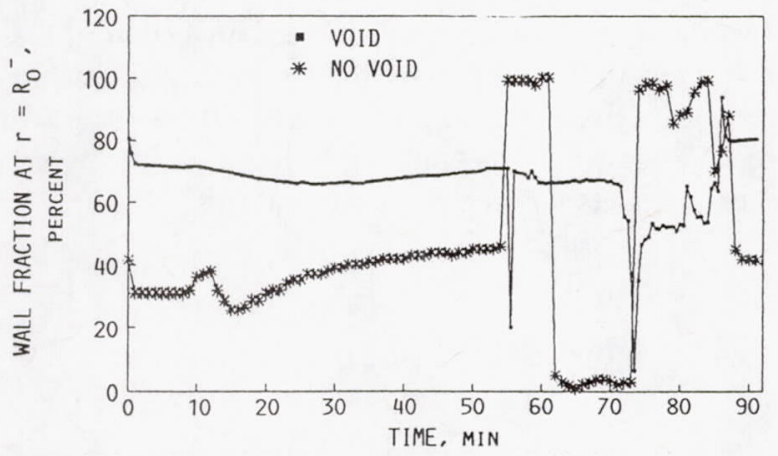

FIGURE 8. - RADIAL HEAT TRANSFER SIDE WALL FRACTION. 
1. Report No.

2. Government Accession No.

3. Recipient's Catalog No.

NASA TM-103124

4. Title and Subtitle

5. Report Date

Two-Dimensional Model of a Space Station Freedom

Thermal Energy Storage Canister

6. Performing Organization Code

7. Author(s)

Thomas W. Kerslake and Mounir B. Ibrahim

8. Performing Organization Report No.

E-5474

10. Work Unit No.

474-10-52

9. Performing Organization Name and Address

National Aeronautics and Space Administration

1. Contract or Grant No.

Lewis Research Center

Cleveland, Ohio 44135-3191

13. Type of Report and Period Covered

Technical Memorandum

12. Sponsoring Agency Name and Address

National Aeronautics and Space Administration

Washington, D.C. 20546-0001

14. Sponsoring Agency Code

15. Supplementary Notes

Prepared for the 25th Intersociety Energy Conversion Engineering Conference cosponsored by the AIChE, SAE, ACS, AIAA, ASME, and IEEE, Reno, Nevada, August 12-17, 1990. Thomas W. Kerslake, NASA Lewis Research Center. Mounir B. Ibrahim, Department of Mechanical Engineering, Cleveland State University, Cleveland, Ohio 44115 .

16. Abstract

The Solar Dynamic Power Module being developed for Space Station Freedom uses a eutectic mixture of LiF-CaF 2 phase-change salt contained in toroidal canisters for thermal energy storage. This paper presents results from heat transfer analyses of the phase-change salt containment canister. A two-dimensional, axisymmetric finite-difference computer program which models the canister walls, salt, void, and heat engine working fluid coolant was developed. Analyses included effects of conduction in canister walls and solid salt, conduction and free convection in liquid salt, conduction and radiation across salt vapor filled void regions and forced convection in the heat engine working fluid. Void shape, location, growth or shrinkage (due to density difference between the solid and liquid salt phases) were prescribed based on engineering judgement. The salt phase change process was modeled using the enthalpy method. Discussion of results focuses on the role of free-convection in the liquid salt on canister heat transfer performance. This role is shown to be important for interpreting the relationship between groundbased canister performance (in 1-g) and expected on-orbit performance (in micro-g). Attention is also focused on the influence of void heat transfer on canister wall temperature distributions. The large thermal resistance of void regions is shown to accentuate canister hot spots and temperature gradients.

17. Key Words (Suggested by Author(s))

18. Distribution Statement

Thermal energy storage; Phase change material; Space

Station Freedom; Solar dynamic power; Void;

Enthalpy method

Unclassified-Unlimited

Subject Category 34

19. Security Classif. (of this report)

Unclassified

20. Security Classif. (of this page)

Unclassified

21. No. of pages

22. Price* 

National Aeronautics and

Space Administration

Lewis Research Center

Cleveland, Ohio 44135

Official Business

Penalty for Private Use $\$ 300$

ADDRESS CORRECTION REQUESTED

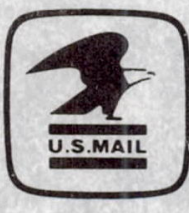

Postage and Fees Paid

National Aeronautics and

Space Administration

NASA 45 